\title{
BASE NACIONAL COMUM CURRICULAR: DISPUTAS NA PRODUÇÃO DE CONHECIMENTO
}

\section{NATIONAL COMMOM CURRICULAR BASE: DISPUTES IN THE KNOWLEDGE PRODUCTION}

\author{
Andressa Graziele Brandt ${ }^{1}$ \\ Edilene Eva de Lima²
}

RESUMO: o movimento de discussão iniciado em 2013 no Brasil, promovido pelo Ministério da Educação (MEC) em prol da elaboração de uma Base Nacional Comum Curricular (BNCC), vem causando um certo desconforto para o campo educacional brasileiro, apresentando-se como uma política curricular que impõe um currículo mínimo, e não uma Base Nacional curricular com forte embasamento teórico. No presente texto, procuramos apresentar uma breve contextualização de como a Base Nacional vem se constituindo, assim como, a partir do nosso ponto de vista, analisar como BNCC está se materializando em política curricular e na produção de conhecimento nas instituições educacionais. Para tanto, as reflexões terão embasamento nos enfoques e nas abordagens observadas na obra das autoras Macedo (2006), Lopes e Macedo (2011), Frigotto (2011), Shiroma e Evangelista (2011), Montaño e Duriguetto (2013), que trazem contribuições significativas para o campo da política curricular.

PALAVRAS-CHAVE: Base Nacional Comum Curricular, política curricular, produção de conhecimento.

ABSTRACT: the discussion movement, initiated in 2013 in Brazil, promoted by the Ministry of Education (MEC) in favor of the elaboration of a National Curricular Common Base (BNCC), has been causing a certain concern to the Brazilian educational field, presenting itself as a curricular policy that It imposes a minimum curriculum and not a national curriculum base with a strong theoretical foundation.

\footnotetext{
${ }^{1}$ Doutoranda - Programa de Pós-Graduação em Educação pela UFSC. Universidade Federal de Santa Catarina - UFSC. Professora - Instituto Federal Catarinense - Campus Camboriú-Santa Catarina-Brasil andressa.brandt@ifc.edu.br 2 Doutoranda - Programa de Pós-Graduação em Educação pela UFSC. Universidade Federal de Santa Catarina - UFSC.Pedagoga - Rede Municipal de Ensino de São José -Santa Catarina-Brasil.edilima_prof@hotmail.com
} 
In the present text, we attempt to present a brief contextualization of how the national base is being constituted, as well as, from our point of view, to analyze how BNCC is materializing in curricular politics and in the production of knowledge in educational institutions. Therefore, the reflections are based on the approaches and observation of the work of Macedo (2006); Lopes and Macedo (2011); Frigotto (2011); Shiroma and Evangelista (2011) e; Montaño and Duriguetto (2013), that bring significant contributions to the field of curricular policy.

KEYWORDS: National Commom Curricular Base, curriculum policy, knowledge production.

\section{Introdução}

O objetivo deste artigo é refletir sobre como a análise da Base Nacional Comum Curricular (BNCC) está se materializando em política curricular e na produção de conhecimento em instituições educacionais. Para explanar sobre o assunto, traremos uma breve contextualização sobre o movimento de criação da BNCC. Nesse cenário, apresentaremos uma análise dessa política curricular a partir da sua materialização e dos movimentos neoliberais capitalistas na sociedade civil atual, os quais influenciam nas políticas educacionais brasileiras.

No Brasil, a partir de 2013, iniciou-se um movimento de discussão nacional promovido pelo Ministério da Educação (MEC) em prol da elaboração de uma Base Nacional Comum Curricular. Este movimento, inicialmente composto por pesquisadores, consultores e especialistas educacionais, buscou envolver também os demais profissionais da educação, os professores, os gestores, os pais e os estudantes, por meio de debates orientados pelas secretarias estaduais e municipais e das universidades.

Além do acesso a elaboração de proposição de BNCC, disponibilizado por meio de participação, via plataforma digital, durante a elaboração da primeira versão do documento da BNCC. Nesta plataforma digital, encontravamse vários documentos explicando a necessidade deste movimento nacional, na tentativa de garantir a participação da comunidade e dos profissionais da educação.

No primeiro parágrafo de um dos documentos disponibilizados na plataforma digital para consulta da população, intitulado Necessidade de Construção de uma Base Nacional Comum, é apresentada a necessidade de elaboração de uma BNCC, bem como a justificativa dos conceitos, das ideias e dos princípios defendidos pelo movimento: 
O direito constitucional à educação é concretizado, primeiramente, com uma trajetória regular do estudante, isto é, acesso das crianças e jovens a uma escola de educação básica na idade legal, depois sua permanência nessa escola, seguida da conclusão das diferentes etapas em que o ensino é organizado, também nas idades esperadas. Concomitantemente, os estudantes devem ainda adquirir os aprendizados de que necessitam para uma vida plena, o que inclui seu desenvolvimento socioemocional e a efetiva inserção na sociedade do conhecimento. (MBNC, 2015, p. 1).

Chama-nos a atenção o trecho inicial do documento, no qual se afirma que o direito constitucional à educação é concretizado, assim como o direito à escola e ao acesso a ela na idade legal, seguidos da permanência e da conclusão das diferentes etapas. Justificar a construção de BNCC baseando-se na argumentação de garantia do direito à educação, ao acesso na idade legal e à permanência parece de certa forma problemático.

A promulgação de uma Base Nacional não garante tais direitos, tendo em vista que outros fatores diretamente ligados à melhoria e à qualidade da educação necessitam de melhorias, como a distribuição justa de renda, o acesso igualitário aos bens sociais, a valorização do magistério, a adoção de políticas sociais igualitárias etc.

Na sequência, justifica-se a elaboração do documento, sem deixar de considerar outros documentos e/ou diretrizes já elaborados no país anteriormente. Entre estes, destacamos: os Parâmetros Curriculares Nacionais (PCN), as Diretrizes Curriculares Nacionais (DCN) para a educação básica, traçadas pelo Conselho Nacional de Educação (CNE), assim como as propostas curriculares elaboradas pelos diversos estados e municípios. Considera-se, nas publicações disponibilizadas no portal do MEC, em matéria sobre a importância da BNCC (2015), que, apesar de haver uma série de ricas discussões e iniciativas em desenvolvimento por todo o país, a ausência de uma BNCC (2015) traz consequências, como o fato de muitos estudantes não adquirirem os conhecimentos e as habilidades que todos deveriam adquirir, o que acarreta grandes desigualdades educacionais.

Várias são as documentações, a exemplo das apontadas acima, que trazem nas suas intenções a garantia do direito à escola para todos, assim como à permanência e à inclusão, como princípio da educação brasileira. A maioria destes documentos foi elaborado com a participação de educadores, gestores, estudantes e comunidades. 
O espaço de participação é uma tentativa de aproximar os conteúdos trabalhados na escola das necessidades e expectativas da sociedade, diminuindo as distâncias entre o saber científico e os saberes oriundos das experiências trazidas pelos sujeitos. Não nos parece crível afirmar que somente através de uma BNCC o direito à educação se concretizaria. E muito menos que é a ausência dessa base comum que contribui com as desigualdades educacionais existentes.

\section{Pressupostos teóricos do campo do curricular}

À proposta da BNCC (2015), de que todas as escolas sejam similares e mantenham um currículo comum a todo o país, em nosso julgamento, subjaz uma única forma de ver os estudantes, o que deixa de considerar alguns dos princípios fundantes na constituição do sujeito, sua identidade e cultura, já que a "construção identitária se faz no seu interior" (LOPES; MACEDO, 2011, p. 216).

Para as autoras, cada indivíduo possui sua identidade cultural, e esta, a cada dia, é reconhecida como objeto de atenção no campo curricular. Tornase confusa, difícil de entender e de aceitar a prescrição de um currículo único, já que o próprio MEC tem se incumbido, nos últimos dez anos, de produzir publicações $^{33}$ que valorizam a participação dos sujeitos que compõem as comunidades educativas, incentivando as escolas a considerar nos seus currículos os diferentes saberes e culturas constitutivos destes sujeitos. Diferentes autores, estudiosos do campo curricular (BHABHA, 2003; MACEDO 2004, 2006; LOPES, 2006; CANDAU, 2008; MOREIRA, 2013), também advogam em favor da valorização das culturas dos diferentes sujeitos, da prioridade central do pluralismo cultural nos currículos, em uma perspectiva denominada por eles como intercultural, crítica e emancipatória.

A propósito, segundo Lopes e Macedo (2011), a cultura se refere à ação direta do homem, mediante o emprego da técnica, na transformação física do ambiente, daí a origem de metáforas como cultivar o bom gosto ou a alta cultura, diretamente ligadas à educação.

Macedo (2006) afirma ainda que a cultura não pode ser vista como forma de conflito ou como prática discriminatória que produz a diferença, tampouco o currículo deve ser tido como um cenário em que as culturas lutam por legitimidade; antes, a autora entende o currículo como lugar de cultura, de expressão: “Ou seja, como não é possível selecioná-las para que componham

${ }^{3}$ Entre as publicações, destacamos: As Diretrizes Nacionais para a educação básica e Indagações sobre currículo: diversidade e currículo (2007); Educação como Exercício da Diversidade, da coleção Educação para todos (2007); e Educação Integral - texto Referência para o Debate Nacional (2009).

Rev. Fac. Educ. (Univ. do Estado de Mato Grosso), Vol. 28, Ano 15, № 2 p. 57-73, jul./dez. 2017 
o currículo, o currículo é ele mesmo um híbrido, em que as culturas negociam com a diferença." (MACEDO, 2006, p. 105).

De acordo com Macedo (2006), o currículo pode ser definido como híbrido porque está permeado por relações interculturais e por um poder oblíquo e contingente. Relações estas derivadas dos próprios sujeitos, que também são híbridos em seus pertencimentos culturais, interagindo e produzindo novos híbridos, que não podem ser entendidos como somatórios de culturas de pertencimento. Aqui a noção de cultura é tomada em uma perspectiva de comunicação constante, recomposta "a partir de uma ampla variedade de fontes num processo hibrido e fluido" (MACEDO, 2006, p. 106). Nesse viés,

[...] o currículo seria um espaço-tempo de interação entre culturas. Usando a terminologia de nossas coleções modernas, em que as culturas são vistas como repertórios partilhados de sentidos, poderíamos enumerar um sem número de culturas presentes no currículo. Desde o que chamaríamos de princípios do lluminismo, do mercado, da cultura de massa até repertórios culturais diversos, dentre os quais frequentemente destacamos culturas locais. Mas estar na fronteira significa desconfiar dessas coleções e viver no limiar entre as culturas, um lugar-tempo em que o hibridismo é a marca e em que não há significados puros. (MACEDO, 2000, p. 106).

Questionamos, então, como poderia ser elaborada uma Base Curricular Comum, fixando os conteúdos a serem ensinados nas escolas brasileiras, se nosso país se apresenta tão extenso e com características regionais tão distintas, composto por uma riqueza cultural tão híbrida. Entre as razões que justificam a elaboração de uma BNCC, o documento disponibilizado via plataforma digital, denominado Necessidade de Construção de uma Base Nacional Comum, explicita objetivos de duas naturezas, usualmente referidos como cognitivos e não cognitivos, "que os alunos devem alcançar em sua escolaridade básica, etapa por etapa" (MBNC, 2015, p. 3). Mesmo o documento prevendo a inclusão de uma parte diversificada, exigida pelas características de cada região, as justificativas apregoam que a existência de uma BNCC "auxiliará na construção de uma matriz que especificará as avaliações nacionais" (MBNC, 2015, p. 5). Ou seja, uma forma de facilitar as avaliações em larga escala.

As avaliações padronizadas têm como foco os resultados; ignoram as realidades e as individualidades de cada sujeito, valorizam a formação por competência, a preparação e qualificação para o mercado de trabalho, a em- 
pregabilidade e a padronização dos resultados. Não destacam a valorização da cultura e as diversas realidades locais, a formação do sujeito e o direito à construção da sua identidade única, de tal sorte que sejam respeitadas a sua singularidade e as suas diferenças, tendo em vista que o direito à diversidade abriu um leque de manifestações em todo país em favor de políticas desta natureza. Destacamos ainda a política de educação integral e suas publicações, nas quais se valoriza a inclusão dos saberes e diálogos das comunidades locaisno currículo.

Analisando as publicações presentes no portal da BNCC (2015), no link disponibilizado pelo MEC, verifica-se a preocupação em unificar os conteúdos incluídos nos currículos, ou seja, há uma intenção de selecionar conteúdos para compor o planejamento dos professores em todo o território nacional. Desconsidera-se que esta "seleção é arbitraria e produzida em meio a relações de poder em virtude das quais se exclui muitos outros conhecimentos possíveis de serem ditos e, muitas vezes, necessários de serem tratados" (ABDC; ANPED, 2015 , p. 4). Despreza-se, claramente, a multiplicidade de conhecimentos oriundos da diversidade dos sujeitos que compõe o território nacional.

Nesse sentido, um conjunto de conteúdos produzidos por especialistas em diferentes áreas, que não considera como ponto de partida os protagonistas da escola, mesmo que tenha sido aberto à participação popular, não garante que foram os educadores que participaram e tampouco que se consideraram os diferentes sujeitos e saberes em sua elaboração. Concordamos e reafirmamos a posição dos Curriculistas que elaboraram o oficio no 01/2015/GR, expondo os motivos sobre a Base Nacional Comum Curricular, produzido por uma equipe de pesquisadores vinculados à Associação Nacional de Pós-Graduação e Pesquisa em Educação (ANPED), de que não faz sentido caminhar em direção "aos conteúdos, objetivos e áreas de conhecimento antes de debater e acordar sobre: $O$ que é currículo? O que é avaliação? O que são direitos de aprendizagem?". (2017, p. 4).

Questionamos se uma BNCC elaborada a partir de uma metodologia que considera os objetivos de aprendizagem e a hierarquização dos resultados estaria mesmo preocupada com o direito ao acesso à educação.

Nesse sentido, "a política é interpretada como um guia para a prática, seja para orientar de forma técnica como a prática deve ser desenvolvida, seja para orientar de forma crítica como a prática deveria ser para assumir determinadas finalidades de transformação social" (LOPES; MACEDO, 2011, p. 234).

A reflexão sobre o enunciado proposto nos suscita os seguintes questionamentos: como as escolas recriam as políticas curriculares? Como torná-las 
agentes produtores de alternativas curriculares emancipatórias, superando de forma mais significativa a separação entre política e prática, projeto e implementação curricular? Como tornar os educadores agentes produtores de políticas curriculares emancipatórias? E ainda: é possível que os professores tenham autonomia diante de um currículo prescrito?

Segundo Macedo (2006), o currículo prescrito tem por intenção manter o controle e o poder nas mãos das burocracias estatais, concebendo a prática, totalmente controlada. Para a autora, a maioria dos estudos sobre política curricular divide-se entre o contexto da produção e o contexto da implementação, mascarando a dinamicidade do processo político implícito no currículo e incutindo uma compreensão de poder equilibrada, constituída tanto pelo poder dos poderosos quanto dos subalternos. Além disso, levando em consideração como estes documentos prescritivos chegam às escolas, a autora afirmam que eles limitam a participação do leitor e a produção de sentidos de tal maneira que as diferentes formas de recriação, na maioria das vezes, tornam-se simbólicas.

Lopes e Macedo (2011) também desaprovam os trabalhos de pesquisa sobre a política de currículo no Brasil, cujo único direcionamento, segundo as autoras, seria a crítica aos documentos e projetos em curso, destacando que deveriam ser pesquisas voltadas a investigações teóricas e empíricas sobre políticas de currículo propriamente ditas. Assinalam que, tanto no Brasil quanto no exterior, grande parte das análises dos documentos e projetos curriculares estão mais voltados a críticas do que a investigações relacionadas com as políticas de currículo.

Segundo as autoras, na Inglaterra, as pesquisas sobre políticas de currículo tomaram maior impulso a partir dos anos de 1980, mas no Brasil o surgimento desse campo teve início somente nos anos de 1990, muito provavelmente a partir do impacto causado pela circulação de documentos curriculares e pela efetivação de reformas educacionais em curso nesse período. Lopes e Macedo (2011) destacam ainda que, no período em questão, diferentes autores pautaram-se em uma perspectiva crítica, sustentada por concepções de políticas diferenciadas, dentre as quais se evidenciam a crítica estrutural marxista e a abordagem do ciclo de políticas.

O ciclo contínuo de políticas, segundo Lopes e Macedo (2011), tem como preocupação central a recontextualização que ocorre nas escolas. Como modelo analítico, o ciclo é composto de três contextos inter-relacionados, entendidos como um conjunto de arenas públicas e privadas de ação: contexto de influência (grupos de interesse lutam por discursos políticos); contexto de 
produção do texto político (envolve as agências executivas e legislativas que assinam regulamentações e produzem textos que representam ou tentam representar para as escolas o que é a política como um todo e a sociedade em geral); e o contexto da prática (na qual os textos políticos reproduzidos são interpretados e recriados por duas dimensões: das comunidades disciplinares e das especificidades institucionais).

Dessa forma, o que significa falar em disputas na produção de conhecimento na escola? Segundo Lopes e Macedo (2011, p. 92), "Nesta perspectiva o currículo também não é fixo nem é um produto de uma luta fora da escola para significar o conhecimento legítimo." Desse modo, "[...] não cabe falar em disputa pela seleção de conteúdos, mas disputas na produção de significados na escola [...]" (LOPES; MACEDO, 2011, p. 93), as quais, segundo as autoras, vinculam-se a um processo social comprometido com uma concepção de currículo, de cultura, conhecimento, política, prática e cotidiano.

O entendimento do currículo, como prática de significação, como criação ou enunciação de sentidos, torna inócuas distinções como currículo formal, vivido e oculto. Qualquer manifestação do currículo, qualquer episódio curricular são a mesma coisa: a produção de sentidos. Seja "o currículo escrito ou velado, o currículo é um texto que tenta direcionar o leitor, mas que o faz apenas parcialmente" (LOPES; MACEDO, 2011, p. 42).

\section{Sociedade civil: um espaço para decisões de políticas educacionais}

Lopes e Macedo (2011) afirmam que o modelo capitalista, em seus ciclos de produção, venda, consumo e lucro, apresenta cenários de crise e por isso precisa moldar-se e estrategicamente criar formas de superar as crises cíclicas de superprodução e superacumulação inerentes ao sistema, como, por exemplo, adotar a medida de abrir as fronteiras, abandonando as políticas de proteção de fronteiras.

Seguindo a mesma lógica, para Montaño e Duriguetto (2013), o capital, sob hegemonia financeira, precisa promover a desregulação da economia e das fronteiras nacionais, a fim de viabilizar a constituição das condições para sua acumulação: aumento dos juros, redução dos gastos fiscais e diminuição do custo da força de trabalho.

Isso nos faz refletir sobre a seguinte questão: por que o sistema neoliberal, que é a forma de política econômica vigente no atual Estado, preside as políticas públicas? Segundo Montaño e Duriguetto (2013), a crise global, 
nas suas duas formas típicas - a socialdemocracia e o socialismo real -, permite a compreensão da regressão social promovida pelo neoliberalismo. A crise global tem as seguintes expressões: o colapso do socialismo real, com a queda do Muro de Berlim; a crise do capitalismo democrático, com exigências antidemocráticas.

Segundo os mesmos autores, o que fica desse processo é que a crise do capitalismo democrático, enfrentada pelo capital com uma profunda reestruturação capitalista sob o comando hegemônico do capital financeiro, substituirá o regime de acumulação fordista-keynesiano por um novo regime de acumulação flexível, porém mantendo substancialmente as determinantes do capitalismo na sua fase monopolista.

Portanto, a globalização, segundo os autores, é o processo de mundialização do capital iniciado com a expansão marítimo-comercial no século $\mathrm{XV}$ e potencializado pelo desenvolvimento tecnológico, que, com a incorporação dos países da extinta União Soviética ao mercado capitalista, consegue abarcar praticamente o planeta inteiro. Todo esse processo teve um impacto significativo e negativo nas lutas de classe, produzindo um número enorme de desempregados e fazendo com que a classe trabalhadora assumisse uma postura individual e defensiva, causando sua desarticulação e a perda de unidade e identidade nas lutas. O que nos leva a refletir sobre as seguintes questões: como a crise do capital e o projeto neoliberal têm influenciado o projeto societário educacional do Brasil e como isso materializa-se nos currículos dos cursos de formação de professores e da educação básica?

Para o modelo neoliberal, a educação desempenha um papel-chave no crescimento econômico e no emprego, daí sua ênfase na necessidade de 'bons' professores. Nesse viés, caberia ao governo desenvolver políticas capazes de fazer do ensino uma escolha profissional atraente, estabelecer os conhecimentos e competências necessários aos professores, bem como recrutá-los, selecioná-los e empregá-los, retendo professores de qualidade nos estabelecimentos escolares e ainda elaborando e colocando em prática ações políticas relativas ao exercício da docência. Dessa mesma forma, o Estado influencia na elaboração dos currículos e nas diretrizes, criadas para corresponder às demandas originadas pelo modelo capitalista.

Vivemos um tempo em que o capital flui livremente, e o mercado instância mais mencionada do que compreendida (LOPES 2006) - parece se tornar o espaço de decisão tanto das questões públicas quanto das privadas. As mudanças nas agências de atividade política do Estado - os governos - não são mais compreendidas como fundamentais para a modificação de políticas 
que interferem em nossa vida cotidiana. Não porque tenhamos uma decisão pública na sociedade civil, mas porque o espaço público não é mais visto como o espaço da decisão política.

As ideias das autoras Lopes e Macedo (2011) guardam em comum a interpretação de que as políticas só podem ser realizadas por três grandes grupos da estrutura social: o aparelho do Estado, que busca atender ao interesse do capital; a economia; e as várias instituições da sociedade civil.

Segundo as autoras, (LOPES; MACEDO, 2011, p. 241), a educação, sob a égide do neoliberalismo, tende a deixar de ser financiada pelo Estado, diminuindo as ações burocráticas. E mesmo que ele mantenha o controle das atividades, seu poder de intervenção, no entanto, diminui. As decisões até então tomadas pelo Estado serão reguladas por mecanismos privados e corporativos de mercado.

Segundo Montaño e Duriguetto (2013, p. 143), o Estado constituise em um tipo privilegiado de organização dentro e a serviço da sociedade capitalista, que o criou e o mantém. Assim, dever ser visto como uma instituição própria do sistema capitalista, orientada para: a) os fundamentos da acumulação capitalista; b) promover a legitimidade da ordem social vigente; c) responder às demandas das classes trabalhadoras.

Dessa maneira, o Estado não pode ser creditado apenas aos interesses do capital; deve ser visto também como produto de fortes e permanentes lutas de classes por direitos políticos, sociais e democráticos, por legislação trabalhista e por política e serviços sociais e assistenciais.

As atuais políticas educacionais brasileiras são uma tentativa de diminuição da conservação social e das desigualdades de oportunidade e acesso à educação entre as classes sociais? A parceria público-privada não é um retrocesso no campo da educação pública, gratuita e de qualidade que queremos para o Brasil?

Com isso, o Estado, em vez de alargar o fundo público na perspectiva do atendimento a políticas públicas de caráter universal, fragmenta as ações em políticas focais, que amenizam os efeitos sem alterar substancialmente as suas determinações. E, dentro dessa lógica, é dada ênfase aos processos de avaliação de resultados balizados pelo produtivismo e à sua filosofia mercantil, em nome da qual os processos pedagógicos são desenvolvidos, mediante a pedagogia das competências.

Dessa forma, a educação no Brasil está a serviço do mercado? Esse processo não deveria estar ligado fortemente às questões sociais do nosso país? Afinal, educamos para quem e para quê? 
Segundo Frigotto (2011), nesse contexto, as concepções de educação centradas na pedagogia histórico-crítica ficam submetidas dominantemente à concepção mercantil e, portanto, também as possibilidades de uma educação unitária, unilateral e as suas exigências em termos das bases materiais que Ihes dão viabilidade, disputadas quando da definição do Plano Nacional de Educação (PNE), explicitadas em diferentes Conferências Nacionais, as quais afetam a educação no conjunto da federação, mormente a educação básica.

O texto nos faz refletir sobre até que ponto foi democrático os processos de construção dos Planos Nacional, Estaduais e Municipais de Educação, amplamente discutidos pela comunidade no âmbito das suas respectivas áreas de abrangência.

Quais as influências do pensamento educacional mercantil nas políticas públicas educacionais de todas as modalidades da educação brasileira?

Para Frigotto (2011), o movimento dos empresários emtorno do Compromisso Todos pela Educaçãoe sua adesão ao Plano de Desenvolvimento da Educação (PDE), contrastada coma história de resistência ativa de seusaparelhos de hegemonia e de seus intelectuaisàs teses da educaçãopública, gratuita, universal, laica e unitária, revela a um só tempo o carátercínico do movimento e a disputa ativa pela hegemonia do pensamento educacional mercantil no seio das escolas públicas.

Há um último aspecto de grande abrangência que nos conduz a sustentar que a primeira década do século XXI foi dominantemente marcada pelas concepções e práticas educacionais mercantis típicas da década de 1990, seja no controle do conteúdo do conhecimento, seja nos métodos de sua produção ou ainda na socialização, autonomia e organização docentes. Três mecanismos articulados estão em ampla expansão nas secretarias estaduais e municipais de educação. O primeiro mecanismo chega ao chão da escola calcado na ideia de que a esfera pública é ineficiente e, portanto, torna-se necessário estabelecer parcerias entre o público e o privado. Assim, percebemos que pouco avançamos ou que nada mudou em relação à década anterior no tocante à política educacional brasileira.

Estamos pagando um preço muito caro pela privatização do nosso ensino. Tome-se como exemplo o que Frigotto (2011) diz a respeito dos institutos privados ou Organizações não Governamentais (OnG). De acordo com Frigotto(2011), cabe a eles selecionar o conhecimento, condensá-lo em apostilas ou manuais, orientar a forma de ensinar, definir os métodos de ensino e os critérios e processos de avaliação e controle dos alunos e dos professores. Dessa forma, questionamos: não possuem nossos professores formação e 
autonomia suficientes para a definição de seus currículos e das políticas de currículo desse país?

De acordo com Frigotto (2011), o segundo mecanismo, decorrente do anterior, talvez o mais proclamado pela mídia, notadamente pelas revistas semanais, é justamente atacar a natureza da formação docente realizada nas universidades públicas, com o argumento de que os cursos de pedagogia e de licenciatura se ocupam muito com a teoria e com análises econômicas sociais inúteis, em lugar de ensinar ao professor as técnicas do "bem ensinar". A pressão do mercado para a adoção de uma pedagogia dos resultados se materializa nas DCNs para a formação de professores, nas quais uma carga horária substancial é dedicada à formação prática dos futuros professores, deixando aflorar a concepção de caráter técnico que subjaz à atual formação de professores no país.

Segundo o autor, a avaliação dos professores e sua certificação encontram-se em meio ao mesmo processo; são mecanismos de controle, como também aponta Frigotto (2011). Uma das receitas desses manuais, em letras maiores, destacadas em negrito pela reportagem, apregoa que "avaliar o desempenho individual dos professores permitiria não só premiá-los de forma mais justa, mas também fazer algo mais importante: entender como eles trabalham".

Para Frigotto (2011), esse último aspecto define o terceiro mecanismo, condição para que os dois primeiros tenham sucesso. Trata-se das ações para desmontar a carreira e organização docentes mediante a adoção de políticas de prêmio, a exemplo do que fazem as escolas que, remunerando os professores de acordo com sua produtividade em termos do quantitativo de alunos aprovados, alcançam melhor desempenho de acordo com os critérios oficiais. Os institutos ou organizações privadas, para assessorar ou atuar diretamente nas escolas, têm a incumbência de avaliar professores e alunos de acordo com os conteúdos, métodos e processos prescritos.

Dessa forma, ao pensarmos sobre a política da educação brasileira e sua concepção na primeira década do século XXI, emerge a crítica feita por Frigotto (2011, p. 248): "o que se desenvolve atualmente é a uma concepção mercantil de educação"(grifos nossos).

A fim de combater essa concepção, é importante que exista um campo para a formação de professores como intelectuais orgânicos, com autonomia e liberdade para construir as políticas públicas de currículo do país.

Para o entendimento das políticas de currículo como políticas culturais, tais sistemas de representação - o mercado, a produção, o consumo, a 
cultura comum, o currículo nacional - precisam ser considerados de forma a entender os efeitos discursivosdesses sistemas simultaneamente simbólicos e materiais (LOPES, 2006, p. 37).

Nesse sentido, para Macedo (2006), a produção dos currículos formais e a vivência do currículo são processos cotidianos de produção cultural, que envolvem relações de poder tanto em nível macro quanto em nível micro. Em ambos, são negociadas diferenças. De ambos, participam sujeitos culturais com seus múltiplos pertencimentos.

\section{Dimensões Conclusivas}

O processo de discussão e materialização da BNCC, ocorrido em 2017, deu-se em meio a discussões entre intelectuais e legisladores nacionais de uma forma 'ampla', mas podemos dizer que essa política curricular não foi construída com base nas propostas curriculares de Estados e Municípios, assim como também não considerou (ou foram mesmo esquecidos) os documentos de orientações nacionais produzidos pelo próprio Ministério da Educação, já citados aqui anteriormente, os quais até agora foram utilizados como fontes cujas orientações continham as diretrizes necessárias e fundantes a serem seguidas e contempladas pelos currículos escolares.

A atual BNCC (2017) causa um certo desconforto para o campo educacional brasileiro, gerando desconfiança entre os intelectuais e as entidades do campo do currículo, pois impõe um currículo mínimo, e não uma base nacional curricular mínima com forte embasamento teórico.

A presente desconfiança e indignação por parte dos educadores e intelectuais da área se acentua quando se toma ciência, nos documentos disponibilizados pelo MEC em sua plataforma digital, das justificativas para a elaboração de uma base curricular única, a ser seguida por todo o território brasileiro, com as quais se pretende justificar que tal base comum auxiliará na construção de uma matriz que, por sua vez, especificará as avaliações nacionais. Desse modo, fica demonstrada que a avaliação em larga escala é a maior preocupação e também a justificativa para se seguir um currículo único, que acabará influenciando a autonomia democrática das Instituições de Ensino Superior (IES) na elaboração de seus projetos pedagógicos dos cursos de formação inicial de professores, ou seja, das licenciaturas.

De acordo com Shiroma e Evangelista (2011), um projeto para a educação de um país não pode se limitar à perseguição de índices e metas; ao contrário, precisa explicitar a que projeto de sociedade se vincula. Ações 
que pretendem mudar resultados ou índices sem considerar o investimento em melhorias das condições materiais necessárias para tanto podem até ser inócuas para a relação ensino-aprendizagem, mas são bastante eficazes para operar profundas reorganizações no interior das instituições educacionais; competição, concorrência e segmentações são efeitos da implantação dessas avaliações que produzem rankings (SHIROMA; EVANGELISTA, 2011, p. 144-145).

Levando em consideração os pensamentos dos diferentes autores citados no decorrer deste texto, bem como as diferentes leituras realizadas, cumpre esclarecer que a definição de uma BNCC está vinculada a demandas apresentadas pela sociedade atual, preocupada em responder às necessidades apresentadas pelo capital, ou seja, há preocupação em elevar o índice educacional e, por conta disso, a educação passa a ser pauta nas diferentes agendas de desenvolvimento econômico de vários países, em função não apenas da necessidade com que é tratada como também da sua importância para sociedade do conhecimento.

Há ainda a intenção de controlar os conteúdos que são repassados, para que a educação possa responder às exigências do novo mercado. Apesar disso, não há preocupação real com o magistério, tampouco um reconhecimento social que traduza o verdadeiro papel que o professor desempenha na sociedade.

O processo de construção dos conhecimentos escolares, no chão das escolas, depende de implementação por parte dos professores, tornando-se então fundamental que eles consigam ampliar seus conhecimentos e ensinamentos para além de um currículo mínimo, instituindo um percurso formativo que permita aos discentes aprender a pensar e construir seus conhecimentos, no qual eles, os docentes, figurem como intelectuais orgânicos, formados para promover a emancipação humana.

Macedo (2006) pensa nos currículos escolares como espaço-tempo de fronteira e, portanto, como híbridos culturais, ou seja, como práticas ambivalentes que incluem o espaço e o temo em um jogo em que nem a vitória nem a derrota jamais serão completas:

Entendo-os como um espaço-tempo em que estão mesclados os discursos da ciência, da nação, do mercado, os "saberes comuns", as religiosidades e tantos outros, todos também híbridos em suas próprias constituições. É um espaço-tempo em que os bens simbólicos são "descolecionados", "desterritorializados", "impurificados" num processo que explicita a fluidez das fronteiras entre as culturas do eu e do outro e torna menos óbvias e 
Nesse processo, não podemos deixar de questionar como a proposta de construção de uma BNCC, como política curricular, da forma com que vem sendo elaborada e defendida pelo MEC, tendo em vista um país de extensão territorial e cultural tão vasto como o Brasil, poderia incluir a todos e apresentar condições de ampliar os processos formativos dos docentes e demais profissionais da educação com vistas a construir os conhecimentos escolares de uma forma emancipatória e a tornar os docentes intelectuais orgânicos, e não apenas para servir à voz do neoliberalismo, ou seja, formar mão de obra para o mercado de trabalho?

Parece-nos que, sob a ótica da necessidade de uma BNCC (2017), está embutida a cultura de metas e resultados, tão recomendados pelas diferentes instâncias que defendem a educação como produtora de resultados.

Além disso, o antagonismo em relação à imprevisibilidade do chão da escola, qual o conhecimento colocado na BNCC, definida por objetivos-conteúdos no documento lançado pelo MEC para consulta pública em 2015, enviada ao Conselho Nacional de Educação (CNE), em 6 de abril de 2017 e aprovada em 15 de novembro de 2017. Processo esse, que de certa forma, causou um sentimento de uma falsa participação coletiva para a construção do referido documento, pois não houve espaços de discussão e para ouvir as entidades da educação e aqueles que discordam da proposição de um currículo prescrito, o qual não considera que as escolas são locais de produção de seus currículos

O que consta, que no processo de construção do documento da BNCC, somente foi ouvido os professores dos conhecimentos específicos de cada disciplina, e não dos pensadores do campo do currículo, que vêm há cinquenta anos pensado a teorização curricular nesse país.ão se está observando que o nosso país é culturalmente diverso, e uma educação tracejada por meio de um documento pautado em direitos e objetivos destinado à aprendizagem de um sujeito tratado como se fosse único, o qual, consequentemente, torna-se destinatário de políticas homogêneas de ensino e aprendizagem, neste cenário, não é relevante para o avanço das políticas educacionais.

Do mesmo modo, nesse processo, percebe-se o forte instrumento de gestão e a busca por contemplar ações de caráter neoliberal, pois a concepção de currículo expressa no documento é vaga e unilateral, busca contemplar o desempenho do aluno sem qualquer diálogo com o campo do currículo e seus pesquisadores, os quais expuseram uma forte opinião contrária à BNCC, manifestada publicamente em documento produzido pelo Grupo de Trabalho 
Currículo, da ANPEd, em 2015.

Defendem os curriculistas que o currículo é um conhecimento poderoso, produzido no chão da escola por intelectuais orgânicos que possuem uma profissionalidade digna de ser valorizada, com oportunidade para construção de saberes fomentados pelo processo coletivo de ensino e aprendizagem, valorizando a amplitude cultural e a diversidade do contexto educacional.

Dessa forma, pensamos ser de suma importância o desenvolvimento de intelectuais orgânicos, que são participantes ativos nos processos de construção e reformulação dos currículos das escolas da educação básica e do ensino superior. Portanto, lutamos contra qualquer processo que busque tornar os professores meros instrutores técnicos do currículo.

\section{Referências}

ASSOCIAÇÃO BRASILEIRA DE CURRÍCULOS (ABDC); ASSOCIAÇÃO NACIONAL DE PÓS-GRADUAÇÃO E PESQUISA EM EDUCAÇÃO (ANPED). Oficio no 01/2015/GR. Exposição de Motivos sobre a Base Nacional Comum Curricular. Produção do GT de currículo da Anped. Rio de Janeiro, 9 de janeiro de 2015. Disponível em: <https://goo.gl/hNmyYK>. Acesso: 22 fev. 2016.

BHABHA, H. O Local da cultura. Belo Horizonte: UFMG, 2003.

BRASIL. Ministério da Educação. O PNE 2011-2022: Metas e Estratégias. Brasília: MEC, [2011?]. Disponível em:<https://goo.gl/XDpXa2>. Acesso em: 20 jan. 2015.

BRASIL.Ministério da Educação.Necessidade de Construção de uma Base Nacional Comum.Brasília: MEC, 2009.Disponível em: <https://goo.gl/jcNYU6>. Acesso: 22 jan. 2015.

BRASIL.Ministério da Educação. Base Nacional Comum Curricular: educação é a base. Brasília: MEC, 2017.Disponível em: <https://goo.gl/Ar58kT>. Acesso: em 28 dez.2017

CANDAU, V. M. Direitos humanos, educação e interculturalidade: as tensões entre igualdade e diferença. Revista Brasileira de Educação, v. 13 n. 37, p. 45-56, jan./abr. 2008. Disponível em: <http://www.scielo.br/pdf/rbedu/ v13n37/05.pdf>. Acesso: 20 fev. 2016.

FRIGOTTO, G. Os circuitos da história e o balanço da educação no Brasil na primeira década do século XXI.Rev. Bras. Educ [online]. vol. 16, n. 46, p. 235254, 2011. Disponível em: <https://goo.gl/7u2cJC>. Acesso em: 20 fev. 2016. 
LOPES, A. C.Discursos nas políticas de currículo. Currículo sem Fronteiras, v. 6, n.2, p. 33-52, jul./dez. 2006.

LOPES, A. C.; MACEDO, E. Teorias de Currículo. São Paulo: Cortez, 2011.

MACEDO, E. Currículo: cultura, política e poder.Currículo sem Fronteiras,Porto Alegre, v. 6, n. 2, p. 98-113, 2006.

. Currículo e hibridismo: para politizar o conceito de cultura. Educação

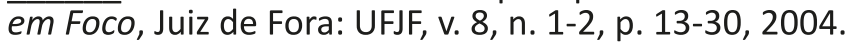

. Currículo como espaço-tempo de fronteira cultural. Revista Brasileira

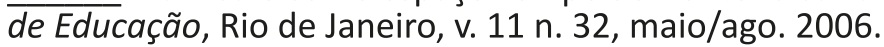

MONTAÑO, C.; DURIGUETTO, M. L. O Estado no capitalismo monopolista e as lutas de classes. In: Estado, classe e movimento social. 3. ed. São Paulo: Cortez, 2011. p. 139-179.

MONTAÑO, C.; DURIGUETTO, M. L. A (contra) Reforma do Estado no regime de acumulação flexível (pós-1973) - Consenso de Washington para a América Latina. In: Estado, classe e movimento social. 3. ed. São Paulo: Cortez, 2011. p. $180-220$.

MOREIRA, A. F. B. (Org.). Currículo: Políticas e Práticas. 13. ed. Campinas, SP: Papirus, 2013. (Coleção Magistério: Formação e Trabalho Pedagógico).

MOVIMENTO PELA BASE NACIONAL COMUM (MBNC). Necessidade e construção de uma Base Nacional Comum. Movimento pela base, [S.I], 2015. Disponível em: <https://goo.gl/8k7Y6D>. Acesso em: 20 abr. 2017.

SHIROMA, E. O; EVANGELISTA, O.Avaliação e responsabilização pelos resultados: atualizações nas formas de gestão de professores. Perspectiva, Florianópolis, v. 29, n. 1, 2011, p. 127-160.

Data de recebimento: 08.05.2017

Data de aceite: 17.03 .2018 